\title{
HUMOR: SIM. É POSSÍVEL TRADUZI-LO E ENSINAR A TRADUZI-LO
}

\begin{abstract}
RESUMO: O presente artigo tem como objetivo apresentar uma resposta à pergunta feita por John Robert Schmitz em seu artigo publicado na edição da TradTerm 3, 1996. Este estudo tentará mostrar que, guardadas as dificuldades inerentes ao ato tradutório, é possivel tanto traduzir humor quanto ensinálo a traduzir. Assim, será apresentada uma atividade realizada com alunos de tradução em que se tenta mostrar alguns dos mecanismos (lingüísticos, pragmáticos e culturais) utilizados para se criar o humor e como podemos proceder para recuperálos e manter o mesmo, ou quase o mesmo, efeito humorístico no texto traduzido.
\end{abstract}

Adauri Brezolin*

Unitermos: discurso humorístico; tradução; ensino de tradução.

Ao ler o artigo "Humor: É Possivel Traduzi-lo e Ensinar a Traduzi-lo?” (TradTerm, 3, 1996) do Prof. Dr. John Robert Schmitz, fiquei bastante motivado a oferecer uma resposta, não em forma de debate, é óbvio, mas como uma tentativa de poder contribuir para uma discussão que, além de complexa, é bastante controvertida. Esta contribuição não pretende aprofundar-se em teorias sobre o humor (o que é brilhantemente feito por Schmitz). Pretende, no entanto, levantar algumas questões pertinentes à tradução de humor, mais especificamente por intermédio de uma atividade realizada em sala de aula com o simples objetivo de ilustrar algumas colocações feitas pelo referido professor.

(*) Faculdade Ibero-Americana/ Universidade São Judas Tadeu, doutorando na área de Língua Inglesa e Literaturas Inglesa e NorteAmericana, FFLCH, USP.

TradTerm, 4(1), $1^{\circ}$ semestre de 1997, p. 15-30 
A complexidade e a controvérsia relativas à tradução e ao ensino da tradução de humor ficam bem evidenciadas por Schmitz (1996), ao apresentar, por intermédio das vozes de vários estudiosos do assunto, que não há um consenso quanto à efetiva possibilidade de tradução de textos humorísticos, mas que há, no entanto, uma concordância generalizada quanto ao fato de esse tipo de texto mostrar-se como um grande desafio aos tradutores. Esse desafio parece ter origem nos vários mecanismos utilizados para se criar o humor,- mecanismos que ocorrem em diversos níveis: lingüístico, pragmático e cultural, apenas para citar alguns. Daí concordarmos plenamente com Schmitz (1996), quando diz que:

O estudo do humor por parte de alunos de tradução, possibilita o aprofundamento da sensibilidade lingüistica e cultural dos mesmos (p. 87).

Além disso, como veremos na atividade realizada com alunos de tradução, o uso de piadas, sobretudo, parece bastante apropriado, uma vez que, por serem curtas, constituem um universo textual completo, permitindo aos alunos conhecerem o texto todo, o que, muitas vezes, não acontece quando é solicitado ao aluno traduzir apenas pequenos trechos de obras literárias, artigos jornalísticos, etc, ou seja, o aluno não consegue apresentar uma solução aceitável por desconhecer o texto como um todo. O leitor mais atento poderá estar inferindo que advogamos uma teoria de tradução que prestigie somente o texto original; ao contrário, nossa visão de tradução, que será apresentada posteriormente, vai além das teorias tradicionais de tradução.

Portanto, antes de apresentarmos nossas bases teóricas, gostariamos de voltar ao texto que fez nascer tal reflexão. Ainda no resumo, Schmitz (1996) alega que "A resposta à pergunta se é possivel traduzir o humor é: em termos. Quando o humor depende do contexto ou da situação, não existe problema na tradução de piadas e chistes. Todavia, quando se trata de humor que envolva ambigüidade fonológica, semântica ou sintática, é mais dificil traduzir, devido às diferenças estruturais entre a língua de partida e a língua de chegada" ( $p$. 87). Se levássemos a res- 
posta "em termos" às últimas conseqüências, poderíamos deduzir que, ao lidarmos com piadas cujo humor não depende do contexto ou da situação, sua tradução seria impraticável. Esse destino à impraticabilidade, felizmente, é modificado e, ao continuar, Schmitz (1996) esclarece alguns pontos: "Cumpre observar que o critério para a tradução de piadas de uma determinada língua para outra não deve ser baseado na reconstrução de um determinado texto humorístico original” ( $p$. 88). Daí advém nossa discordância com a resposta "em termos"; parece-nos que uma resposta mais apropriada seria: "sim, é possivel traduzir o humor.", pois, tenha sido o humor criado com base no contexto ou situação, ou num mecanismo lingüístico (fonológico, semântico ou sintático), a tradução de humor sempre será uma tarefa dificil, tão dificil quanto traduzir qualquer outro tipo de texto, porém praticável.

Assim, nossa resposta à pergunta se é possivel traduzir humor é: sim. Pois, para nós, traduzir um texto humorístico ou não-humorístico não se baseia em teorias de tradução que tentam, a todo custo, recuperar o significado do original. Dessa maneira, nossa visão de tradução tenta percorrer caminhos que desmascarem a ilusão de que podemos compreender o original somente por intermédio dos significantes que nossos olhos perscrutam na hora da leitura. Segundo Arrojo (1992a):

Toda tradução revela sua origem numa interpretação exatamente porque o texto de que parte, o chamado "original", somente vive através de uma leitura que será - sempre e necessariamente - também produto da perspectiva e das circunstâncias em que ocorre (p. 78).

Assim, o significado do texto de partida está muito mais naquele que o lê, pois esse texto começa apenas a existir no momento em que está sendo lido. Ademais, como Arrojo (1992a) observa: "qualquer tradução, por mais simples e despretensiosa que seja, traz consigo as marcas de sua realização: o tempo, a história, as circunstâncias, os objetivos e a perspectiva de seu realizador" (p. 78).

Dentre esses fatores que marcam a realização de uma tradução, gostariamos de salientar os objetivos e associá-los a um outro trecho do texto de Schmitz (1996) em que diz: 
essencial não é a fidelidade ao texto original mas o comprometimento de (re)criar um efeito humorístico na língua de chegada (p. 88).

Parece-nos que esse "(re)criar um efeito humorístico" na língua de chegada está intimamente ligado aos objetivos do empreendimento tradutório e do meio em que irá se realizar: oral ou escrito. Assim, esse comprometimento, no caso de piadas, pode ser visto sob, pelo menos, dois prismas. O primeiro que nos ocorre seria a situação de um intérprete de conferências que, diante de um conferencista bastante engraçadinho, tivesse de recontar uma piada, como simples recurso de retórica, ou seja, uma piada que não fosse relevante ao conteúdo da palestra. Aí, o comprometimento ao efeito humorístico parece-me bastante apropriado, ou seja: fazer a platéia rir num determinado momento. Para isso bastaria recorrer a uma piada já institucionalizada e simplesmente satisfazer sua necessidade para tal situação. Cabe, aqui, dizer que esse recurso é corriqueiramente utilizado e recomendado pelos veteranos da interpretação. Nesse caso, a inserção de qualquer piada teria o simples objetivo de preencher uma necessidade pragmática, que ultrapassaria os limites dos significantes. A segunda situação, que diz respeito à tradução escrita parece, no entanto, requerer mais cautela por tocar o texto de partida muito mais de perto e, conseqüentemente, seus objetivos. Afinal de contas, é exatamente esse fator que estamos destacando. Mesmo na tradução escrita, poderíamos recorrer a esse expediente, caso a piada não fosse relevante ao texto em si. Contudo, se estivéssemos traduzindo piadas de outras culturas para leitores que não entendessem a língua de origem, ou adaptando piadas a outra cultura, nossa atitude seria bem diferente. Nesses casos, haveria a necessidade de nos apegarmos, inevitavelmente, a um ponto de partida. Não há como negarmos a existência desse ponto de partida, desse texto de origem, que nos leva a vários destinos igualmente satisfatórios e apropriados e em função do leitor final do texto traduzido.

Em suma, o que torna viável a tradução de uma piada (e outros tipos de texto) é necessariamente nossa concepção de tradução - concepção essa que, além de prever as várias inter- 
pretações de cada leitor, aceita o recurso de recriação como a única saída para alguns casos - um texto humorístico que ocorra em nível fonológico, por exemplo.

Passaremos, a seguir, à atividade realizada com alunos de tradução ${ }^{1}$ em que lhes foi solicitado traduzir piadas do inglês para o português. Tentaremos, assim, demonstrar que é possível ensinar a traduzir, ou seja, que é possivel levar o aluno a uma maior reflexão sobre o ato tradutório e conduzi-lo a resultados mais aceitáveis.

A seleção dos textos a serem traduzidos, neste caso as piadas, deve, preferencialmente, refletir uma preocupação não apenas com o desafio apresentado pelo tipo de texto, mas também com as imposições criadas pela estrutura das línguas envolvidas. No que tange às piadas, possuem diferentes mecanismos em suas estruturas internas que, muitas vezes, não são conhecidas ou, até mesmo, não são percebidas pelos alunos. Assim, antes de iniciarem a traduzir ou durante o tempo em que estão traduzindo, o professor pode interferir salientando os elementos que criam o humor. Por exemplo, diversos aspectos tanto culturais quanto lingüisticos na língua de partida podem ser trazidos à discussão antes de se buscar uma solução na língua de chegada.

Cabe aqui ressaltar que, por acreditarmos que o resultado de uma tradução está intimamente ligado aos objetivos que se propõem, antes de iniciarmos a tradução, fatores tais como: cliente, público-alvo, tempo, registro, gênero e estilo foram estabelecidos. Essa proposta tem como base as idéias de Ruuskanen (1995) que sugere que o tradutor deva construir um leitor antes de iniciar a tradução. Mesmo porque, como nos adverte a própria autora, a simples mudança de um dos fatores estaria afetando o resultado como um todo. Assim, antes de iniciarmos a tradução das piadas, a seguinte tabela foi estabelecida com os alunos, ou seja, houve consenso de que a tradução deveria ser realizada dentro dos seguintes parâmetros:

(1) Esta atividade foi realizada na Faculdade Ibero-Americana, São Paulo, em 1995. 


$\begin{array}{ll}\text { Cliente } & \text { editora } \\ \text { Público-alvo } & \text { brasileiros com faixa etária variada } \\ \text { Tempo } & \text { uma semana } \\ \text { Registro } & \text { situações cotidianas } \\ \text { Gênero } & \text { humorístico } \\ \text { Estilo } & \text { coloquial }\end{array}$

A seguir, apresentaremos o corpus utilizado para tal atividade:

1. How many Poles does it take to wash a car? Two. One to hold the sponge and one to move the car back and forth. (Ruch, Attardo \& Raskin, 1993:135

2. Diner: "Waiter, what's this fly doing in the soup?

Waiter: "Looks like the breast-stroke, sir." (Nash, 1985:115, apud Yamaguchi, 1988:325)

Essas duas piadas referem-se à situação em que não encontramos problemas na tradução (Schmitz, 1996), uma vez que o humor depende do contexto ou situação. A piada número 1, evidentemente, faz sentido na sociedade americana onde os poloneses são ridicularizados e tidos como ignorantes. Ao tradutor bastaria, então, referir-se ao grupo étnico que é alvo de chacota em sua cultura de chegada. No Brasil, todos sabemos, os portugueses representam esse grupo. Como veremos adiante, a maioria dos alunos não teve dificuldade em traduzir tal piada. Para a piada número 2 , bastaria ao tradutor providenciar à pergunta do cliente uma resposta cuja leitura fosse igualmente literal. Os alunos também não tiveram dificuldade em solucioná-la.

As piadas seguintes requerem um tratamento mais elaborado do leitor/ouvinte, pois o humor reside em aspectos lingüísticos, portanto, os mais dificeis de traduzir (Schmitz, 1996). Vejamos os niveis em que podem ocorrer:

\section{Lexical}

3. "I don't think I've ever seen a \$200 bill."

"Really? I have one. I'll show it to you."

TradTerm, 4(1), $1^{\circ}$ semestre de 1997, p. 15-30 
"You have a $\$ 200$ bill?"

"Of course, it's from my dentist." (True 1981: 63, apud Laurian, 1992:115)

4. Question: What has four wheels and flies?

Answer: A garbage truck. (Dolitisky, 1992:38)

\section{Fonológico}

5. Famed Chinese diplomat attended gala reception in Washington in early part of the day. Senate lady, trying to make polite conversation, asked, "Dr. Wong, what 'nese' are you? Chinese, Japanese, or Javanese? "Chinese", he replied, "and you, madam? What 'kee' are you? Monkey, donkey, or yankee?” (True 1981: 38, apud Laurian, 1992:114)

\section{Morfológico}

6. "Teacher, "said Bertie, "I can't do this problem because I ain't got no pencils".

"Now, Bertie, "she said, 'It's a pencil. We don't have any pencils. They don't have any pencils.' "Do you understand?" "No." admitted Bertie. "What happened to all them pencils?"

(True 1981:106, apud Laurian, 1992:117)

Em termos gerais, essas piadas concentram seu efeito no aspecto cognitivo, que está intimamente ligado à teoria da incongruência (Morreall, 1983). Segundo essa teoria: "amusement is an intellectual reaction to something unexpected, illogical, or inappropriate in some way." (p. 15).

Portanto, traduzir essas piadas está longe de ser uma tarefa fácil; requer muito mais que simplesmente manipular dicionários e encontrar equivalentes textuais. Como a tradução em geral, traduzir piadas é uma atividade heurística que abrange habilidades em quatro grandes áreas: "language, general knowledge, comprehension and re-expression" (Deslile, 1988:109). 
A seguir, vejamos como tudo isso pode ser aplicado em sala de aula. Embora saibamos que a tradução seja uma atividade bastante complexa, a maioria dos leigos e até mesmo os alunos iniciantes de cursos de tradução acham que, assim que terminarmos o texto, ele está pronto para ser impresso. Ledo engano. Sabemos que esse texto poderá e pode ser mudado a cada nova revisão. Porém, na vida real as coisas são bem diferentes. Há um dia em que temos de entregar a tradução sem passarmos por muitas revisões. No ambiente de sala de aula, no entanto, por mais artificial que possa parecer, o professor pode treinar seus alunos visando a objetivos mais amplos, ou seja, a tradução, da mesma forma que a redação, está provisoriamente terminada. Isso não quer dizer tampouco que seu texto possa ser entregue de qualquer maneira. Com tal atividade, fica claro que o aluno pode aprender a desenvolver uma maior criticidade perante $o$ texto traduzido. Em vez de o professor simplesmente recolher as traduções e corrigi-las, apontando os erros principalmente, ele pode fazer o aluno passar por um processo mais interessante e produtivo que, certamente, o tornará mais consciente do que seja traduzir.

A proposta sugerida aqui para o ensino de tradução de humor (que pode ser aplicada a outros textos também) inclui, então, várias sessões em que o aluno compartilha com o professor e colegas suas tomadas de decisão, enquanto traduz seu texto. Para a realização dessa atividade, os alunos passaram pela seguinte seqüência:

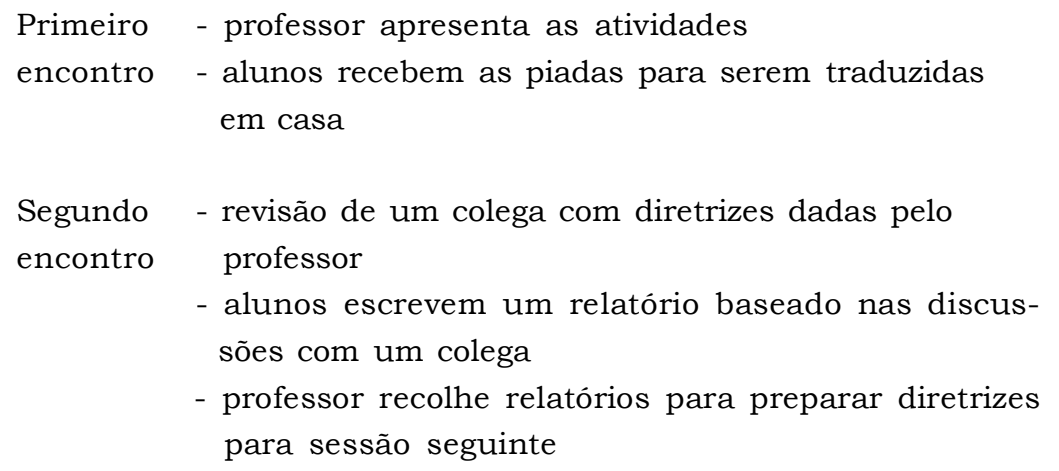


- alunos re-fazem tradução em casa, usando sugestões dos colegas

Terceiro - revisão de colega seguindo diretrizes do professor (com encontro base no relatório)

- alunos preparam a cópia final em casa, seguindo as sugestões dos colegas

As idéias para esse tipo de atividade têm como base os princípios do "process writing approach", ou seja:

reading and writing are seen as interacting linguistic forces through which students will develop their overall academic proficiency. Students are guided through numerous reading strategies that extract information from the printed page and then, through a process writing approach, they are shown that the act of writing itself helps to create, develop, and refine thinking processes. (Brown, Cohen \& O’Day, 1991: vii).

Da mesma maneira que redigir um texto de sua própria autoria exige tomar decisões, o processo tradutório, enquanto visto como possivel em sala de aula, pode proporcionar ao aluno situações que o façam refletir sobre suas próprias escolhas e outros pontos de vista. Cabe aqui lembrar que, embora essas atividades ou o processo de aprendizagem como um todo pareçam artificiais demais, o aluno estará tendo a oportunidade de ver seu trabalho avaliado e, o mais importante, a oportunidade de alterá-1o, buscando elevar sua qualidade, o que nem sempre é possivel aos tradutores profissionais em virtude da exigüidade de tempo, por exemplo.

Assim, com a utilização de tais atividades de auto-avaliação e verificações em duplas, os alunos estão sendo expostos a diferentes pontos de vista e aprendendo as convenções de determinados estilos discursivos sobre os quais ainda não têm domínio. Além disso, os alunos são estimulados a desenvolver auto-

TradTerm, 4(1), $1^{\circ}$ semestre de 1997 , p. 15-30 
confiança e lutar por escolhas que acharem acertadas, pois o objetivo é mostrar que não existem interpretações únicas e, conseqüentemente, não existe uma única tradução válida.

Mostraremos, a seguir, algumas soluções encontradas pelos alunos. As piadas originais e suas traduções aparecem abaixo:

\section{Piada 1}

How many Poles does it take to wash a car? Two. One to hold the sponge and one to move the car back and forth. (Ruch, Attardo \& Raskin, 1993:135)

Quantos portugueses são necessários para lavar um carro? Dois. Um para segurar a esponja e outro para movimentar o carro pra frente e pra trás.

\section{Piada 2}

Diner: - "Waiter, what's this fly doing in the soup?

Waiter: - "Looks like the breast-stroke, sir." (Nash, 1985:115, apud Yamaguchi, 1988:325)

Cliente: - Garçom, o que esta mosca está fazendo na minha sopa?

Garçom: - Me parece que está praticando nado de peito, senhor.

Cliente: - Garçom, o que esta mosca está fazendo na minha sopa?

Garçom: - Está me parecendo nado de costas./ Praticando nado borboleta, senhor.

Cliente: - Garçom, o que esta mosca está fazendo na minha sopa?

Garçom: - Não se preocupe não, ela só está treinando para as Olimpiadas de 96. / Treinando para as próximas Olimpiadas, eu acho!

Cliente: - Garçom, o que esta mosca está fazendo na minha sopa?

Garçom: - Acho que ela está se preparando para a competição de natação da próxima semana, senhor. / Nada,

TradTerm, 4(1), $1^{\circ}$ semestre de 1997, p. 15-30 
está apenas nadando. / Parece que está praticando natação.

Cliente: - Garçom, o que esta mosca está fazendo na minha sopa?

Garçom: - Parece que ela está se afogando.

Cliente: - Garçom, o que esta mosca está fazendo na minha sopa?

Garçom: - Não sei, parece ter tido um ataque do coração.

Cliente: - Garçom, o que esta mosca está fazendo na minha sopa?

Garçom: - Se o senhor parar de mexer a colher, ela conseguirá sair viva do prato.

Essas duas piadas não representaram grandes problemas aos alunos por razões já esclarecidas anteriormente. No entanto, cabe mencionar que, uma vez detectado o mecanismo utilizado na piada original, basta buscar um outro igualmente efetivo na língua de chegada. Ou seja, para a Piada 2, por exemplo, bastaria ao garçom dar uma resposta inesperada ao fato; porém, por se tratar de tradução, a situação inicial (mosca na sopa) deveria ser mantida.

\section{Piada 3}

"I don't think I've ever seen a \$ 200 bill."

"Really? I have one. I'll show it to you."

"You have a \$ 200 bill?"

"Of course, it's from my dentist." (True 1981: 63, apud

Laurian, 1992:115)

- Nunca vi uma nota de 200 reais!

- Como não? Eu tenho uma.

- Você tem uma!

- Claro. A nota fiscal do meu dentista./ A nota promissória do banco.

Nesse caso, já precisamos fazer alguns acréscimos, pois a ambigüidade contida no item lexical do original não se resolve com uma palavra apenas. Assim, para mantermos o humor, foi 
necessário traduzir uma de suas acepções e adjetivá-la. Houve, no entanto, alguns alunos que mantiveram a tradução literal e, obviamente, apresentaram algo que não poderia mais ser chamado de piada. Esse tipo de tradução foi considerado insatisfatório.

\section{Piada 4}

Question: What has four wheels and flies?

Answer: A garbage truck. (Dolitisky, 1992:38)

- O que tem quatro rodas e voa?

- Um carro de polícia.

A partir dessa piada, mais especificamente, as coisas começaram a ficar bem mais dificeis, pois a ambigüidade dá-se por meio de uma mudança de classe gramatical, ou seja, na primeira leitura pensamos no verbo to fly (voar) flexionado na terceira pessoa do singular do presente do indicativo e, conseqüentemente, imaginamos um novo tipo de aeronave. No entanto, vemos que se trata de flies plural de fly (mosca) e um outro tipo de veículo. Buscar a ambigüidade dessa mesma maneira em língua portuguesa é simplesmente impossivel. Mas, depois de muito esforço e criatividade, achamos que a solução apresentada é satisfatória. Nesse caso, cria-se a mesma ambigüidade, mas lidamos com a polissemia do verbo voar, cujos significados, além de outros, podem ser: "sustentar-se ou mover-se no ar por meio de asas ou de aeronaves" e "correr velozmente" (Novo Dicionário Aurélio, p. 1786). Assim, o leitor/ouvinte da piada traduzida também pensa num novo tipo de aeronave; percebe, no entanto, que se trata de algo que se locomove de maneiras diferentes.

\section{Piada 5}

Famed Chinese diplomat attended gala reception in Washington in early part of the day. Senate lady, trying to make polite conversation, asked, "Dr. Wong, what 'nese' are you? Chinese, Japanese, or Javanese? "Chinese", he replied, "and you, madam? What 'kee' are you? Monkey, 
donkey, or yankee?" (True 1981: 38, apud Laurian, 1992:114)

Um famoso diplomata chinês chega à recepção de gala em Brasília e é recebido pela senhora que tenta puxar papo perguntando: - Que tipo de nês o senhor é, Dr. Wong? Chinês, japonês ou javanês? - Chinês - respondeu não muito satisfeito com a pergunta. - E a senhora, que tipo de eira é? Estrangeira, maloqueira ou brasileira?

Umfamoso diplomata chinês compareceu à recepção de gala na embaixada da Polônia em Washington e, durante a madrugada, uma senadora, tentando ser gentil, perguntou a ele: - Dr. Wong, que tipo de ês o senhor é? Chinês, japonês ou javanês? - Chinês - respondeu ele. - E a senhora, que tipo de aca é a madame? Macaca, bruaca ou polaca?

Embora as duas sugestões dadas não utilizem as mesmas imagens, ou seja, animais e nacionalidade no original, elas conseguem causar o humor por meio do mesmo mecanismo (fonológico). Uma outra sugestão dada e que parece ser a mais feliz é a seguinte:

Um famoso diplomata chinês chega à recepção de gala em Brasília e é recebido pela senhora que tenta puxar papo perguntando: - Que tipo de nês o senhor é, Dr. Wong? Chinês ou japonês? - Chinês - respondeu não muito satisfeito coma pergunta. - E a senhora, que tipo de eira é? Toupeira ou brasileira?

Uma das perguntas rotineiramente feita pelos alunos é:Mas isto pode ser feito? Nossa resposta é: - Sim. Contanto que levemos em conta nossos objetivos.

Quais seriam os argumentos para aceitarmos tal tradução? Em primeiro lugar, parece que optar por apenas duas nacionalidades já representa um forte argumento, pois dificilmente incluiriamos javanês como uma nacionalidade confundivel com

TradTERm, 4(1), $1^{\circ}$ semestre de 1997, p. 15-30 
os asiáticos mais comumente encontrados no Brasil. Em segundo lugar, estariamos sendo mais coerentes com a idéia do criador da piada, ou seja, igualar o americano a um animal que não fosse provido de muita inteligência e, assim, toupeira parece satisfazer essa comparação e, obviamente, cria a sonoridade desejada para rimar com brasileira. Além disso, estaríamos atendendo a nossos objetivos pragmáticos de maneira mais eficiente, quer seja, causar humor para brasileiros.

\section{Piada 6}

"Teacher, " said Bertie, "I can't do this problem because I ain't got no pencils".

"Now, Bertie, "she said, 'It's a pencil. We don't have any pencils. They don't have any pencils.' "Do you understand?" "No." admitted Bertie. "What happened to all them pencils?" (True 1981:106, apud Laurian, 1992:117)

- Professora! - chamou Joãozinho. A gente não podemos fazer a lição porque a gente não temos lápis.

- Joãozinho, só uma coisa. - disse ela. - Preste atenção! Eu não tenho lápis. Nós não temos lápis. A gente não tem lápis. Entendeu?

- Não. - confessou ele. - Ué, o quê aconteceu com todos os lápis?

Caso escolhêssemos o mesmo tipo de erro (dupla negativa) cometido pela criança americana, isso passaria despercebido em português, pois tal prática é perfeitamente possivel nesta língua. Nesse caso, o tradutor deve buscar elementos característicos da fala de uma criança que possam ser considerados erros. Assim, a utilização incorreta de a gente com verbo no plural parece bastante natural para uma criança em fase de alfabetização.

A tradução de texto humorístico ou não-humorístico é, assim, vista como uma atividade intelectual interligada à compreensão, conhecimento geral, língua e re-expressão. Uma atividade que não apenas admita as várias interpretações de seu leito-

TradTerm, 4(1), $1^{\circ}$ semestre de 1997, p. 15-30 
res, mas que também aceite que o texto traduzido exista em função dos objetivos a que se propõe, considerando o texto original apenas como um ponto de partida.

A tradução de piadas, portanto, é um processo que vai além da simples manipulação de dicionários, pois requer muito esforço, imaginação e criatividade. Ao propor essas atividades de autoavaliação e verificação em duplas, percebemos que os alunos têm a oportunidade de se confrontarem com suas limitações, o que não é visto aqui de maneira negativa, mas sim como o momento que têm para tentar superá-las, ao discutir pontos relevantes com seus colegas de sala. Dessa maneira também, o professor deixa, em parte, de ser o único provedor de respostas. Com essa troca de informações, os alunos percebem que o seu texto traduzido pode ser sempre alterado para melhor. Isso não significa que todos os problemas serão resolvidos. Os alunos, no entanto, tornam-se mais conscientes da complexidade do ato tradutório e buscam soluções mais aceitáveis baseadas nessa reflexão.

Conforme foi demonstrado, esperamos ter respondido à pergunta inicial de maneira satisfatória. $O$ humor pode ser tanto traduzido quanto ensinado, contanto que tenhamos o cuidado de deixar claros alguns fatores, ou seja, para que o humor seja traduzido e, principalmente, mantido é necessário que o tradutor: (a) conheça as linguas envolvidas muito bem para perceber onde a regra está sendo rompida para criar o humor; (b) tenha interpretado e compreendido o conteúdo da piada, fazendo uso de bom senso e inteligência e (c) tenha se expressado considerando não apenas os padrões da lingua de chegada, mas também as necessidades do público-alvo.

\section{Referências Bibliográficas}

ARROJO, R. (org.) (1992a) O signo desconstruido. Implicações para a tradução, a leitura e o ensino. Campinas, Pontes.

(1992b) Tradução. In: JOBIM, J. L. (org.) Palavras da Crítica.

Rio de Janeiro, Imago, pp. 411-442.

TradTERm, 4(1), $1^{\circ}$ semestre de 1997, p. 15-30 
ATTARDO, S., RASKIN, V. \& RUCH, W. (1993) Toward an empirical verification of the General Theory of Verbal Humor. Humor, 6-2, pp. 123-136.

DELISLE, J. (1988) Translation: an interpretive approach. (Translated by Patricia Logan and Monica Creery). Ottawa, University of Ottawa Press.

DOLITSKY, M. (1992) Aspects of the unsaid in humor. Humor, 5-1/2, pp. 33-43.

FERREIRA, A. B. de H. (1986) Novo Dicionário Aurélio. Rio de Janeiro, Nova Fronteira.

LAURIAN, A.-M. (1992) Possible/impossible translation of jokes. Humor, 5-1/2, pp. 111-127.

MORREALL, J. (1983) Taking Laughter Seriously. Albany/New York, State University of New York.

RUUSKANEN, D. D. K. (1995) Creating the other: A pragmatic translation tool. Third language international conference on teaching translation and interpreting: "New horizons". Helsingor, Denmark, June 9-11, 1995.

SCHMITZ, J. R. (1996) Humor: É possivel traduzi-lo e ensinar a traduzi-lo? In: TradTerm - Revista do Centro Interdepartamental de Tradução e Terminologia, FFLCH, USP, 3: 87-97.

TradTerm, 4(1), $1^{\circ}$ semestre de 1997, p. $15-30$ 